\title{
Effects of genotype on hematological and serum biochemical responses of turkey hens to stress
}

\author{
Krzysztof Damaziak $^{1}$, Monika Michalczuk ${ }^{1}$, Żaneta Zdanowska-Sasiadek ${ }^{2}$, Artur Jóźwik ${ }^{2}$, \\ Dariusz Gozdowski $^{3}$, Anna Siennicka ${ }^{1}$, and Jan Niemiec ${ }^{1}$ \\ ${ }^{1}$ Department of Animal Science, Warsaw University of Life Sciences, \\ Ciszewskiego 8, 02-786 Warsaw, Poland \\ ${ }^{2}$ Department of Animal Improvement, Institute of Genetics and Animal Breeding of the Polish Academy of \\ Sciences, Postępu 36A, 05-552, Magdalenka, Poland \\ ${ }^{3}$ Department of Experimental Design and Bioinformatics, Warsaw University of Life Sciences, \\ Nowoursynowska 159, 02-786 Warsaw, Poland \\ Correspondence to: Krzysztof Damaziak (krzysztof_damaziak@sggw.pl)
}

Received: 29 September 2016 - Revised: 2 January 2017 - Accepted: 6 January 2017 - Published: 30 January 2017

\begin{abstract}
Stress accompanying animal production is both an indicator of welfare and a factor that affects economic parameters. Dynamic development of alternative poultry production systems such as outdoor, free range or ecological, strives to achieve best-quality products and to improve the living conditions of birds. Apart from the type and intensity of the external stimuli, the response to stress is determined genetically. Poultry rearing in the aforementioned systems requires selecting the appropriate genotype of birds, often including crosses of fast-growing and slow-growing lines. The objective of this study was to demonstrate differences in the physiological response to stress of fast-growing (FG) and slow-growing (SG) turkeys and their crosses: $\mathrm{SF}$ ( $\mathrm{SG} \times \mathrm{FG}$ ) and FS $(\mathrm{FG} \times \mathrm{SG})$, based on hematological and biochemical blood analyses. Blood was sampled from 30 turkey hens from each of four genotypes, aged 14 weeks, subjected to standard pre-slaughter handling procedures. Compared to FG and FS turkeys, the SG and SF birds had a high total protein concentration, a higher heterophil $(H)$ / lymphocyte $(L)$ ratio and a higher concentration of cortisol. In turn, the FG turkeys had the highest activity of enzymes: alanine transaminase, aspartate transaminase, lactate dehydrogenase, creatine kinase. Conversely, the FS turkeys had the highest concentrations of total cholesterol and low-density lipoprotein (LDLC) and the lowest concentration of cortisol. Significant positive effects of crossing were reported for total protein, cholinesterase and cortisol. Effects of crossbreeding on the percentage of $H$, concentrations of total cholesterol, and LDLC and activity of aspartate transaminase in blood of the crosses were significant but negative and more dependent on the sire line. Except for albumins, whose concentration in blood of crosses was higher compared to birds of pure lines, there were no advantages of heterosis. Negative heterosis was estimated for creatinine, the enzymes alanine transaminase and lactate dehydrogenase, and for cortisol. The most similar regarding creatinine, bilirubin, albumins, total protein, $H, L$ and $H / L$ were the FS and SF groups. The greatest differences were in the following parameters: triglycerides, total cholesterol, high-density lipoprotein (HDLC), LDLC, glucose and lactate, which occurred between the pure lines of turkeys. Study results demonstrate various responses to stress in the analyzed groups of turkeys, with the level of stress measured with hematological and biological blood markers being mostly determined by additive genetic variation, and to a lesser extent by the maternal and sire effects.
\end{abstract}




\section{Introduction}

Stress is induced by one or a few stimuli that disrupt body homeostasis and evoke adverse outcomes (Jóźwik et al., 2003; Siegel, 1995; Śliwa-Jóźwik et al., 2002). In the natural environment, a short-lasting stress stimulus leads to the rapid mobilization of body resources, thereby increasing the chance for escape or defense (Forkman et al., 2007). Stressors associated with the commercial production of poultry (e.g., cold, crating, feed and water deprivation, social tension, transport, manual restraint) induce deleterious effects including energy wastage; decreased growth, feed conversion, egg production and product quality; delayed maturation, compromised hatchability, decreased immunocompetence, development of feather pecking, pain, and even death (Odeh et al., 2003a, b). Intensification of these negative effects depends on the type of stimulus, its intensity and exposure time as well as on the genetic determinants of an individual animal. The genetic effects on stress responses have been thoroughly investigated in the populations of livestock (Rosochacki et al., 2003; Luc et al., 2013). Not much attention has, however, been devoted in this respect to domestic fowl. Nevertheless, Odeh et al. (2003a, b), who studied the population of diallel crosses of Japanese quail for corticosterone concentration in blood plasma, demonstrated that heterozygous birds (maternal effect) were less susceptible to environmental factors compared to homozygotes. These dependencies were, however, not investigated in turkeys. Identification of genetic elements that affect the feeling of fear and response to stress in this species seems to be important considering the dynamically developing production of slaughter turkeys. Furthermore, fearful birds are more difficult to handle, which increases the risk of injury to both birds and handling personnel. Simultaneously, the interest of consumers in alternative poultry production systems (outdoor, free range, ecological) prompts the producers to search for novel genetic groups of these birds, often with a medium-fast growth rate, including crosses of slow-growing turkeys (label type) and fastgrowing commercial lines. Sparse investigations comparing the behavioral traits of fast- and slow-growing lines of turkey indicate that they differ in the vulnerability to both long-term and short-term stress (Huff et al., 2007; Ilori et al., 2011; Erasmus et al., 2015). It seems appropriate, therefore, to investigate the model of the physiological response to stress in various populations of turkeys and to elucidate principles of inheritance of the analyzed parameters. Considering the above, the objective of this study was to determine - based on selected blood parameters - the physiological response of turkeys from two genetic lines and their reciprocal crosses to stress induced during standard procedures linked with transport to a slaughterhouse and pre-slaughter handling.

\section{Material and methods}

The turkeys were slaughtered in commercial production. According to the Act of 21 January 2005 on experiments with animals (Act 2005 No. 33, item 289), the production was not an experimental procedure and therefore did not require application to and consent of the National Ethical Commission at the Ministry of Science and Higher Education in Poland.

\subsection{Birds, transport conditions, and slaughter}

The turkeys resulted from reciprocal crossing of fast-growing commercial BUT Big-6 line (FG) and slow-growing local Bronze turkey line (label type) (SG). The genetic distances established based on the genetic molecular analysis of pure lines FG and SG used in this study reached 0.257 (unpublished data). Turkeys were allocated to three replicate pens, containing 60 birds per SG, FS and FG genotype. The SF turkeys were divided into replications of 47, 47 and 48 birds. All turkeys were kept under the same conditions with access to a free range. Housing conditions were described and production performance of the turkeys was thoroughly investigated and reported in previous studies (Damaziak et al., 2015,2016 ). Once turkey hens completed the 15 th week of life, they were fasted for $8 \mathrm{~h}$, caught and loaded onto an openfenced trailer covered with a tarpaulin. The transport period was from 06:30 to 08:30 LT with an average outside temperature of $12 \pm 3{ }^{\circ} \mathrm{C}$, an inside temperature of $24 \pm 4^{\circ} \mathrm{C}$, and the inside relative humidity of $79 \%$. The truck drove with an average speed of $50 \mathrm{~km} \mathrm{~h}^{-1}$, on a village road in Mazovia, Poland. After transport, the birds were unloaded, hung on shackles of a slaughter line, stunned using an electrical water bath stunner $(380 \mathrm{~V}, 50 \mathrm{~Hz}$ sine wave alternating current for $4 \mathrm{~s}$ ) and immediately slaughtered by exsanguination from the left jugular vein.

\subsection{Blood sample preparation and analyses}

During exsanguination, ca. $4 \mathrm{~mL}$ blood samples were collected to test tubes without the anticoagulant from 30 turkey hens of each genetic group (from 10 birds selected at random from each replication). Then, $1 \mathrm{~mL}$ samples were taken for spot testing for blood heterophils $(H)$ and lymphocytes $(L)$. Blood smears were air-dried and stored in darkness. Within 3 days, they were stained using a Diff-Quick kit (Medion Diagnostics, Düdingen, Switzerland). Having been preserved in a fixing solution, the samples were stained with two solutions containing eosin and thiazine. Afterwards, the slides were rinsed with distilled water and air-dried, then stored in darkness. Blood smears were scanned with a 104c Nikon microscope $(\times 1000)$ and the first 100 leucocytes were differentiated (heterophils, eosinophils, basophils, lymphocytes, monocytes). The $H$ / $L$ was calculated by dividing the number of heterophils in these 100 leucocytes by the number of lymphocytes. The remaining $3 \mathrm{~mL}$ of blood was centrifuged 
Table 1. Means, standard error of the mean (SEM) and orthogonal contrasts on biochemical and hematological values in serum of female turkeys from different genetic groups.

\begin{tabular}{|c|c|c|c|c|c|c|c|c|}
\hline \multirow[t]{2}{*}{ Parameter } & \multicolumn{4}{|c|}{ Means for turkey strains } & \multirow[t]{2}{*}{ SEM } & \multirow[t]{2}{*}{$\begin{array}{l}\text { Additive } \\
\text { effects }\end{array}$} & \multirow[t]{2}{*}{$\begin{array}{l}\text { Cross } \\
\text { effects }\end{array}$} & \multirow[t]{2}{*}{$\begin{array}{r}\text { Percentage } \\
\text { heterosis }\end{array}$} \\
\hline & SG & SF & FS & FG & & & & \\
\hline Creatinine $\left(\mu \mathrm{mol} \mathrm{L}^{-1}\right)$ & $8.42^{\mathrm{b}}$ & $7.03^{\mathrm{ab}}$ & $6.37^{\mathrm{a}}$ & $7.60^{\mathrm{ab}}$ & 0.61 & NS & NS & $-16.3^{*}$ \\
\hline Bilirubin $\left(\mu \mathrm{mol} \mathrm{L} \mathrm{L}^{-1}\right)$ & $0.55^{\mathrm{a}}$ & $0.34^{\mathrm{a}}$ & $0.35^{\mathrm{a}}$ & $0.52^{\mathrm{a}}$ & 0.09 & NS & NS & -35.9 \\
\hline Albumin $\left(\mathrm{g} \mathrm{L}^{-1}\right)$ & $7.75^{\mathrm{ab}}$ & $8.55^{\mathrm{b}}$ & $8.10^{\mathrm{ab}}$ & $7.02^{\mathrm{a}}$ & 0.35 & NS & NS & $12.7^{*}$ \\
\hline Total protein $\left(\mathrm{g} \mathrm{L}^{-1}\right)$ & $37.8^{\mathrm{c}}$ & $36.8^{\mathrm{c}}$ & $33.7^{\mathrm{b}}$ & $30.2^{\mathrm{a}}$ & 0.93 & $(-)^{*}$ & $(+)^{*}$ & 3.80 \\
\hline$H(\%)$ & $32.7^{\mathrm{c}}$ & $33.2^{\mathrm{c}}$ & $29.1^{\mathrm{b}}$ & $26.2^{\mathrm{a}}$ & 1.12 & $(+)^{*}$ & $(-)^{*}$ & 5.77 \\
\hline$L(\%)$ & $59.9^{\mathrm{a}}$ & $58.3^{\mathrm{a}}$ & $61.8^{\mathrm{b}}$ & $64.0^{\mathrm{c}}$ & 1.18 & $(-)^{*}$ & NS & -3.07 \\
\hline$H / L$ ratio & $0.54^{\mathrm{b}}$ & $0.57^{\mathrm{b}}$ & $0.47^{\mathrm{a}}$ & $0.41^{\mathrm{a}}$ & 0.04 & $(+)^{*}$ & NS & 9.46 \\
\hline MANOVA $^{1}$ & & & & & .002 & & & \\
\hline
\end{tabular}

Serum analysis of 30 females in each strain. Turkey strains: SG - slow growing; FG - commercial fast growing; reciprocal crossbreed: SF (SG sires $\times$ FG dams); FS (FG sires $\times$ SG dams). $H$ - heterophils; $L$-lymphocytes. Means within a row without a common superscript differ significantly ${ }^{\mathrm{a}-\mathrm{b}} P<0.05$; * differ significantly for additive, cross effects and percentage heterosis $* P<0.05$, where $(+)$ is positive and $(-)$ is negative value; NS - not significant; ${ }^{1}$ multivariate homogeneous groups. Results are based on MANOVA and pairwise multivariate comparisons where $F$ results of Wilks's test indicate significant differences $* * * P<0.05$.

at $4{ }^{\circ} \mathrm{C}$, at $2000 \times \mathrm{g}$ for $10 \mathrm{~min}$. The centrifuged serum (ca. $0.5 \mathrm{~mL}$ sample) was analyzed using a Cobas Integra ${ }^{\circledR}$ 400 Plus biochemical analyzer (Roche Diagnostic, Switzerland), based on spectrophotometry, turbidimetry, fluorescent polarization, and ion-selective potentiometry. The blood samples were determined for activities of alkaline phosphatase, alanine transaminase, aspartate transaminase, bilirubin, cholinesterase, creatine kinase, $\gamma$-glutamyltransferase, lactate dehydrogenase, and lipase. They were also analyzed for the concentrations of specific proteins (albumins), total protein, total cholesterol, high-density lipoprotein (HDLC), low-density lipoprotein (LDLC), triglycerides, creatinine, glucose and lactate. Serum concentrations of cortisol were analyzed using ELISA assay kits (Cayman's Cortisol ELISA Kit) following manufacturer's instructions.

\subsection{Genetic parameter calculations and statistical analyses}

Mean values were compared between the analyzed groups of turkey hens using one-way analysis of variance and Duncan's multiple comparisons test, and in the case of not meeting the assumptions of the variance analysis (lack of normality of distribution based on Shapiro-Wilk test and equality of variances based on Levene's test), the groups were compared with the Kruskal-Wallis test. In all analyses, the level of significance was set at $P \leq 0.05$. Orthogonal contrasts were used for comparison of the two paternal lines minus the additive genetic effect $(0.5(\mathrm{FG}+\mathrm{FS}-\mathrm{SF}-\mathrm{SG}))$. The contrast of the two reciprocal cross effects was determined: 0.5 (SF - FS). Percentage heterosis was expressed as the percentage deviation of the mean of the reciprocal cross or crosses from the mean of the parental lines. Multivariate differences of the analyzed groups of turkey hens were evalu- ated using cluster analysis. The square of Euclidean distance for standardized variables was used as a measure of distance, whereas the grouping of objects was conducted with the Ward's method. Results were presented in the form of dendrograms. The multivariate differences between the groups were additionally evaluated using the multivariate analysis of variance (MANOVA) and Wilks test. All statistical analyses were performed in Statistica Version 12 software (StatSoft, 2013).

\section{Results}

\subsection{Additive genetic effects}

Regarding the analyzed blood parameters of turkeys, the additive genetic variation was an important source of variability for total protein and hematological markers (Table 1). In contrast, no such an effect was confirmed in the case of lipoprotein lipid composition, glucose and lactate (Table 2). The effect of the additive genetic variation was also confirmed for all enzymes except for $\gamma$-glutamyltransferase (Table 3 ) and cortisol concentration (Table 4).

\subsubsection{Comparison of SG and FG lines}

The statistical analysis of the examined parameters of blood serum of turkeys within the pure lines demonstrated that the SG turkeys, compared to FG birds, were characterized by a higher $(P=0.0002)$ concentration of total protein, whereas in the hematological picture - by a lower $(P=0.0215)$ percentage content of $L$ and a higher $(P=0.0120)$ content of $H$. The ratio of leucocytes $(H / L)$ was higher $(P=$ 0.0152 ) in blood of SG turkeys (Table 1). The concentration of triglycerides was significantly higher $(P=0.0149)$ 
Table 2. Means, SEM or medians, lower and upper quartiles (in brackets), and orthogonal contrasts on lipoprotein lipid composition, glucose, and lactate values in serum $\left(\mathrm{mmol} \mathrm{L}^{-1}\right)$ of female turkeys from different genetic groups.

\begin{tabular}{|c|c|c|c|c|c|c|c|c|}
\hline \multirow[t]{2}{*}{ Parameter } & \multicolumn{4}{|c|}{ Means for turkey strains } & \multirow[t]{2}{*}{ SEM } & \multirow[t]{2}{*}{$\begin{array}{l}\text { Additive } \\
\text { effects }\end{array}$} & \multirow[t]{2}{*}{$\begin{array}{l}\text { Cross } \\
\text { effects }\end{array}$} & \multirow[t]{2}{*}{$\begin{array}{r}\text { Percentage } \\
\text { heterosis }\end{array}$} \\
\hline & SG & SF & FS & FG & & & & \\
\hline Triglycerides 1 & $\begin{array}{l}1.32^{\mathrm{b}} \\
(0.46-1.99)\end{array}$ & $\begin{array}{l}0.43^{\mathrm{a}} \\
(0.41-0.55)\end{array}$ & $\begin{array}{l}0.85^{\mathrm{ab}} \\
(0.53-1.16)\end{array}$ & $\begin{array}{l}0.43^{\mathrm{a}} \\
(0.29-0.61)\end{array}$ & - & NS & NS & -19.6 \\
\hline Total cholesterol ${ }^{1}$ & $\begin{array}{l}3.70^{\mathrm{ab}} \\
(3.09-4.10)\end{array}$ & $\begin{array}{l}3.53^{\mathrm{a}} \\
(3.35-3.66)\end{array}$ & $\begin{array}{l}4.68^{\mathrm{b}} \\
(4.32-5.41)\end{array}$ & $\begin{array}{l}4.09^{\mathrm{ab}} \\
(2.69-4.18)\end{array}$ & - & NS & $(-)^{*}$ & 12.5 \\
\hline HDLC $^{1}$ & $\begin{array}{l}2.52^{\mathrm{a}} \\
(2.07-2.91)\end{array}$ & $\begin{array}{l}2.68^{\mathrm{a}} \\
(2.38-2.77)\end{array}$ & $\begin{array}{l}3.12^{\mathrm{a}} \\
(3.09-3.12)\end{array}$ & $\begin{array}{l}3.03^{\mathrm{a}} \\
(2.97-3.12)\end{array}$ & - & NS & NS & 2.10 \\
\hline LDLC & $0.98^{\mathrm{b}}$ & $0.55^{\mathrm{a}}$ & $1.18^{\mathrm{b}}$ & $0.47^{\mathrm{a}}$ & 0.12 & NS & $(-)^{*}$ & 20.0 \\
\hline Glucose $^{1}$ & $\begin{array}{l}18.0^{\mathrm{a}} \\
(17.0-18.3)\end{array}$ & $\begin{array}{l}17.5^{\mathrm{a}} \\
(15.1-18.2)\end{array}$ & $\begin{array}{l}17.6^{\mathrm{a}} \\
(16.6-17.8)\end{array}$ & $\begin{array}{l}10.8^{\mathrm{a}} \\
(5.7-17.2)\end{array}$ & - & NS & NS & 12.7 \\
\hline Lactate & $10.7^{\mathrm{a}}$ & $9.77^{\mathrm{a}}$ & $8.00^{\mathrm{a}}$ & $8.68^{\mathrm{a}}$ & 0.99 & NS & NS & -8.40 \\
\hline \multicolumn{2}{|c|}{ MANOVA $^{2}$} & \multicolumn{7}{|c|}{$F=1.875^{\mathrm{NS}}$} \\
\hline
\end{tabular}

Serum analysis of 30 females in each strains. Turkey strains: SG - slow growing; FG - commercial fast growing; reciprocal crossbreed: $\mathrm{SF}(\mathrm{SG}$ sires $\times$ FG dams); FS (FG sires $\times$ SG dams). HDLC - high-density lipoprotein cholesterol; LDLC - low-density lipoprotein cholesterol. Means or medians within a row without a common superscript differ significantly

${ }^{\mathrm{a}-\mathrm{c}} P<0.05$; * differ significantly for additive, cross effects and percentage heterosis ${ }^{*} P<0.05$, where (-) is a negative value; NS - not significant; ${ }^{2}$ multivariate homogeneous groups. Results based on MANOVA and pairwise multivariate comparisons where $F$ results of Wilks's test indicate significant differences $P<0.05$.

Table 3. Means, SEM or medians, lower and upper quartiles (in brackets), and orthogonal contrasts on enzyme activity in serum $\left(U \mathrm{~L}^{-1}\right)$ of female turkeys from different genetic groups.

\begin{tabular}{|c|c|c|c|c|c|c|c|c|}
\hline \multirow[t]{2}{*}{ Parameter } & \multicolumn{4}{|c|}{ Means for turkey strains } & \multirow[t]{2}{*}{ SEM } & \multirow[t]{2}{*}{$\begin{array}{l}\text { Additive } \\
\text { effects }\end{array}$} & \multirow[t]{2}{*}{$\begin{array}{l}\text { Cross } \\
\text { effects }\end{array}$} & \multirow[t]{2}{*}{$\begin{array}{r}\text { Percentage } \\
\text { heterosis }\end{array}$} \\
\hline & SG & SF & FS & FG & & & & \\
\hline Alkaline phosphatase & $1179^{\mathrm{b}}$ & $996^{\mathrm{ab}}$ & $910^{\mathrm{a}}$ & $809^{\mathrm{a}}$ & 80.4 & $(-)^{*}$ & NS & -4.10 \\
\hline Alanine transaminase ${ }^{1}$ & $\begin{array}{l}7.50^{\mathrm{a}} \\
(7.00-8.00)\end{array}$ & $\begin{array}{l}6.50^{\mathrm{a}} \\
(5.00-8.00)\end{array}$ & $\begin{array}{l}8.00^{\mathrm{a}} \\
(7.00-8.00)\end{array}$ & $\begin{array}{l}18.5^{\mathrm{b}} \\
(13.0-21.0)\end{array}$ & - & $(+)^{*}$ & NS & $-43.7^{*}$ \\
\hline Aspartate transaminase ${ }^{1}$ & $\begin{array}{l}254^{\mathrm{a}} \\
(232-296)\end{array}$ & $\begin{array}{l}302^{\mathrm{ab}} \\
(300-329)\end{array}$ & $\begin{array}{l}374^{\mathrm{bc}} \\
(350-411)\end{array}$ & $\begin{array}{l}700^{\mathrm{d}} \\
(700-700)\end{array}$ & - & $(+)^{*}$ & $(-)^{*}$ & $-28.8^{*}$ \\
\hline Cholinesterase $^{1}$ & $\begin{array}{l}7429^{\mathrm{b}} \\
(712-7910)\end{array}$ & $\begin{array}{l}6474^{\mathrm{ab}} \\
(6318-6976)\end{array}$ & $\begin{array}{l}5335^{\mathrm{a}} \\
(4884-6100)\end{array}$ & $\begin{array}{l}5482^{\mathrm{a}} \\
(4621-6085)\end{array}$ & - & $(-)^{*}$ & $(+)^{*}$ & -6.10 \\
\hline Creatine kinase $^{1}$ & $\begin{array}{l}2000^{\mathrm{a}} \\
(1806-2000)\end{array}$ & $\begin{array}{l}2000^{\mathrm{a}} \\
(2000-2000)\end{array}$ & $\begin{array}{l}2000^{\mathrm{a}} \\
(2000-6333)\end{array}$ & $\begin{array}{l}20000^{\mathrm{b}} \\
(20000-20000)\end{array}$ & - & $(+)^{*}$ & NS & -72.7 \\
\hline$\gamma$-glutamyltransferase ${ }^{1}$ & $\begin{array}{l}1.40^{\mathrm{a}} \\
(0.30-2.20)\end{array}$ & $\begin{array}{l}1.05^{\mathrm{a}} \\
(0.80-1.20)\end{array}$ & $\begin{array}{l}0.95^{\mathrm{a}} \\
(0.80-1.10)\end{array}$ & $\begin{array}{l}0.45^{\mathrm{a}} \\
(0.00-1.10)\end{array}$ & - & NS & NS & 0.90 \\
\hline Lactate dehydrogenase $^{1}$ & $\begin{array}{l}785^{\mathrm{a}} \\
(565-926)\end{array}$ & $\begin{array}{l}771^{\mathrm{a}} \\
(691-880)\end{array}$ & $\begin{array}{l}782^{\mathrm{a}} \\
(710-1071)\end{array}$ & $\begin{array}{l}1200^{\mathrm{c}} \\
(1200-1200)\end{array}$ & - & $(+)^{*}$ & NS & $-18.9^{*}$ \\
\hline Lipase & $4.10^{\mathrm{a}}$ & $4.13^{\mathrm{a}}$ & $4.33^{\mathrm{a}}$ & $5.13^{\mathrm{b}}$ & 0.21 & $(+)^{*}$ & NS & -8.30 \\
\hline MANOVA $^{2}$ & \multicolumn{8}{|c|}{$F=3.880^{* *}$} \\
\hline
\end{tabular}

Serum analysis of 30 females in each strains. Turkey strains: SG - slow growing; FG - commercial fast growing; reciprocal crossbreed: $\mathrm{SF}$ (SG sires $\times$ FG dams); FS (FG sires $\times$ SG dams). Means within a row without a common superscript differ significantly ${ }^{\mathrm{a}-\mathrm{d}} P<0.05{ }^{*}$ differ significantly for additive, cross effects and percentage heterosis ${ }^{*} P<0.05$, where $(+)$ is positive and $(-)$ negative value; NS - differ not significant; ${ }^{2}$ multivariate homogeneous groups. Results based on MANOVA and pairwise multivariate comparisons where $F$ results of Wilks's test indicate significant differences ${ }^{* *} P<0.05$

in blood of SG turkeys, with a higher $(P=0.0365)$ concentration of low-density lipoproteins (LDLC). The serum activity of the analyzed enzymes was in most cases dependent on bird origin. In serum of SG turkeys, analyses confirmed a higher $(P \leq 0.05)$ activity of alkaline phosphatase and cholinesterase and a lower activity of alanine transaminase, aspartate transaminase, creatine kinase, lactate dehydrogenase, and lipase (Table 3). A high concentration of cor- tisol was found in the blood serum of SG turkeys, and its value was significantly higher $(P=0.0002)$ compared to $\mathrm{FG}$ birds (Table 4).

\subsubsection{Comparison of SF and FS lines}

The SF turkeys were characterized by higher concentrations of total protein $(P=0.0194)$ and $H(P=0.0312)$, and by a 
Table 4. Means, SEM and orthogonal contrasts on cortisol concentrations in serum $\left(\mathrm{ng} \mathrm{mL}^{-1}\right)$ of female turkeys from different genetic groups.

\begin{tabular}{|c|c|c|c|c|c|c|c|c|}
\hline \multirow[t]{2}{*}{ Parameter } & \multicolumn{4}{|c|}{ Means for turkey strains } & \multirow[t]{2}{*}{ SEM } & \multirow[t]{2}{*}{$\begin{array}{l}\text { Additive } \\
\text { effects }\end{array}$} & \multirow[t]{2}{*}{$\begin{array}{l}\text { Cross } \\
\text { effects }\end{array}$} & \multirow[t]{2}{*}{$\begin{array}{r}\text { Percentage } \\
\text { heterosis }\end{array}$} \\
\hline & SG & SF & FS & FG & & & & \\
\hline Cortisol & $185.68^{b}$ & $114.77^{\mathrm{ab}}$ & $65.94^{\mathrm{a}}$ & $73.66^{\mathrm{a}}$ & 0.44 & $(-)^{*}$ & $(+)^{*}$ & $-30.4^{*}$ \\
\hline
\end{tabular}

Serum analysis of 30 females in each strains. Turkey strains: SG - slow growing; FG - commercial fast growing; reciprocal crossbreed: $\mathrm{SF}$ ( $\mathrm{SG}$ sires $\times$ FG dams); FS (FG sires $\times$ SG dams). Means within a row without a common superscript differ significantly ${ }^{\mathrm{a}-\mathrm{b}} P<0.05 ;{ }^{*}$ differ significantly for additive, cross effects and percentage heterosis ${ }^{*} P<0.05$, where $(+)$ is positive and (-) negative value

lower $(P=0.0354)$ concentration of $L$ in serum. The ratio of leucocytes $(H / L)$ was lower $(P=0.0415)$ in blood serum of the FS turkeys (Table 1). Considering the lipid components, FS birds had higher $(P \leq 0.05)$ blood serum concentrations of total cholesterol and LDLC cholesterol fraction (Table 2).

\subsubsection{Comparison of SG lines and SF and FS crosses}

Blood samples of SG turkeys revealed a higher $(P=0.0200)$ concentration of $H$ and a lower $(P=0.0259)$ concentration of $L$ compared to FS birds. A higher $(P=0.0051)$ concentration of triglycerides was assayed in blood serum of SG birds that was accompanied by a lower $(P=0.0403)$ content of the LDLC fraction, compared to blood serum samples of SF turkeys (Table 2). Compared to the FS line, blood serum samples of turkeys of the pure SG line were characterized by a higher $(P \leq 0.05)$ concentration of creatinine and total protein (Table 1), alkaline phosphatase and cholinesterase (Table 3$)$, by almost a 3 -fold higher $(P=0.0002)$ concentration of cortisol (Table 4$)$, but by a lower $(P=0.0351)$ concentration of aspartate transaminase (Table 3 ).

\subsubsection{Comparison of FG lines and SF and FS crosses}

The FG line differed simultaneously from both crosses in the lower $(P \leq 0.05)$ concentrations of total protein (Table 1$)$ and in the higher $(P \leq 0.05)$ serum activity of alanine transaminase, aspartate transaminase, creatine kinase, lactate dehydrogenase and lipase enzymes (Table 3). Compared to SF line turkeys, analyses showed a lower $(P=0.0286)$ content of albumins in the blood serum of FG birds (Table 1). The percentage content of $H$ was lower $(P \leq 0.05)$ and that of $L$ was higher $(P<0.05)$ in blood samples of FG turkeys compared to SF and FS birds (Table 1). The FS turkeys were characterized by a higher $(P=0.0030)$ blood serum concentration of the LDLC fraction (Table 2).

\subsection{Non-additive genetic effects}

Significant $(P \leq 0.05)$ positive effects of crossbreeding were confirmed for total protein (Table 1) as well as for activities of cholinesterase (Table 3) and cortisol (Table 4). Negative effects of crossing were confirmed $(P \leq 0.05)$ for the percentage content of $H$ (Table 1), concentrations of total cholesterol and LDLC lipoproteins (Table 2) as well as aspartate transaminase concentration (Table 3) in blood samples of crosses. Values of these parameters were more similar to these determined in the sire line.

Except for albumin content that was significantly higher $(P \leq 0.05)$ in serum samples of the crosses compared to the birds of pure lines (Table 1), no advantages from heterosis were found for any of the analyzed parameters. A significant $(P \leq 0.05)$ but negative heterosis was estimated for the concentration of creatinine (Table 1), and for the activity of alanine transaminase and lactate dehydrogenase enzymes (Table 3) and cortisol (Table 4).

\subsection{Multivariate analyses}

Multivariate analyses MANOVA and pairwise comparison of genotype (crosses) were performed, with division into groups of parameters, wherein the first group was constituted by all parameters presented in Table 1 and Fig. 1, the second group by parameters specified in Table 2 and Fig. 2, and the third group by all parameters presented in Table 3 and Fig. 3 .

The MANOVA analysis (Wilk's test) demonstrated multivariate differences $(P \leq 0.001)$ between genetic groups of turkeys in terms of all parameters specified in Table 1. Dendrogram 1 (Fig. 1) shows explicitly that considering creatinine, bilirubin, albumins, total protein, $H, L$ and $H / L$, the most similar were the groups of turkey crosses (FS and $\mathrm{SF})$. The pure lines of turkeys were in the other homogenous groups, which indicates that they differed both from one another and from crosses. Turkeys of the FG line were most diverging from all other birds. In contrast, no differences $(P=0.053)$ were found for the following parameters: triglycerides, total cholesterol, HDLC, LDLC, glucose and lactate. Based on dendrogram 2 (Fig. 2), it may be concluded that the greatest differences occurred among the pure lines 


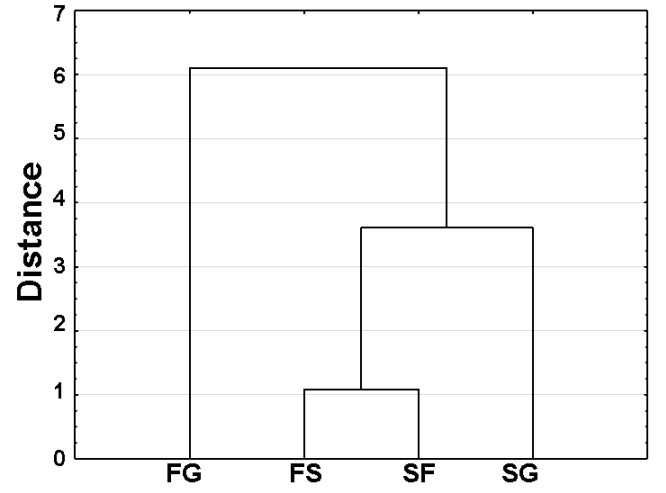

Figure 1. Dendrograms presenting multivariate similarity of the female turkey genotypes ( $\mathrm{SG}$ - slow growing; FG - commercial fast growing; reciprocal crossbreed: SF (SG sires $\times$ FG dams); FS (FG sires $\times$ SG dams)), according to the examined blood parameters: creatinine, bilirubin, albumins, total protein, heterophils, lymphocytes and heterophil / lymphocyte ratio based on cluster analysis (Ward's method of agglomeration).

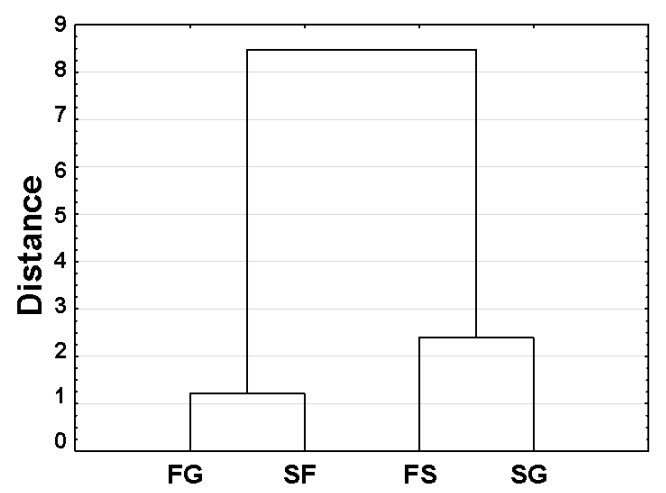

Figure 2. Dendrograms presenting multivariate similarity of the female turkey genotypes (SG - slow growing; FG - commercial fast growing; reciprocal crossbreed: $\mathrm{SF}$ (SG sires $\times$ FG dams); FS (FG sires $\times$ SG dams)), according to the examined blood parameters: triglycerides, cholesterol, high-density lipoprotein, lowdensity lipoprotein, glucose and lactate based on cluster analysis (Ward's method of agglomeration).

of turkeys. The crosses were, in turn, the most similar to the maternal lines $(\mathrm{FG} \approx \mathrm{SF}$ and $\mathrm{FS} \approx \mathrm{SG})$. In the case of the remaining parameters, multivariate differences $(P \leq 0.001)$ were found between the analyzed lines of turkeys (Table 3). The greatest differences in the activity of the selected enzymes were observed between FG turkeys and birds from all other groups that formed one homogenous group (Fig. 3).

\section{Discussion}

The higher $H$ / $L$ ratio in the hematological picture of turkey blood and a 2.5-fold higher cortisol concentration indicated a stronger response of SG birds to stress induced by han-

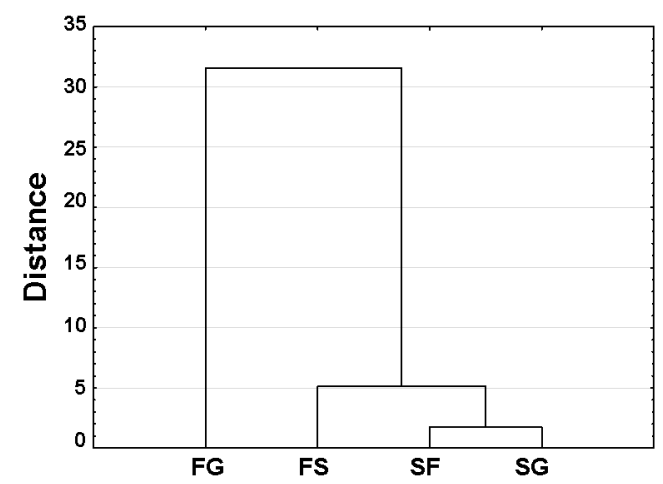

Figure 3. Dendrograms presenting multivariate similarity of the female turkey genotypes (SG - slow growing; FG - commercial fast growing; reciprocal crossbreed: $\mathrm{SF}$ (SG sires $\times$ FG dams); FS (FG sires $\times$ SG dams)), according to the examined blood parameters: alkaline phosphatase, alanine transaminase, aspartate transaminase, cholinesterase, creatine kinase, $\gamma$-glutamyltransferase, lactate dehydrogenase and lipase based on cluster analysis (Ward's method of agglomeration).

dling procedures before and during slaughter, of all pure line turkeys. According to Krams et al. (2011), the level of stress in birds is manifested by, for example, an increasing number of heterophils and by a decreasing number of lymphocytes, which results in a higher $H / L$ ratio. In turn, cortisol is one of the key stress hormones. Being a glucocorticoid, it increases glucose blood concentration during stress responses (Sheriff et al., 2011). Despite no differences found in our study among the SG and FG turkeys in glucose blood concentration, its value higher by $6.5 \mathrm{mmol} \mathrm{L}^{-1}$ in the SG birds (Table 2) could be due to a high concentration of cortisol. The high total protein concentration in the serum of SG birds may be indicative of protein degradation which is aimed at maintaining physiological functions of the body and as such may be treated as a defense response. Besides, increase in the total serum protein concentration could have been due to bird dehydration (Chikumba et al., 2013). As reported by Hochleithner (1994), stress indicators in birds may also include increased activity of alanine transaminase, aspartate transaminase, and lactate dehydrogenase enzymes as well as a reduced concentration of alkaline phosphatase. Differences in their activities between blood samples of turkeys of pure lines examined in this study may point to a more intensive stress response of the FG turkeys (Table 3), especially that, considering all analyzed enzymes, only FG turkeys were in a different interval of the multivariate analysis (Fig. 3). Szabó et al. (2005) demonstrated that high activities of alanine transaminase and aspartate transaminase and decreasing with age activity of alkaline phosphatase indicated the intensive growth and expressed muscle hypertrophy as a result of single-sided selection for meat production and high white glycolytic muscle mass. It may be speculated that the pre-slaughter handling, which includes catching, transport 
and hanging on shackles, is considerably a greater physical effort to heavy birds than to the turkeys of lighter lines. It may, to some extent, be confirmed by a nearly 8 -fold higher concentration of creatine kinase determined in blood of FG than in SG turkeys (Table 3). Creatine kinase is also an indicator of the intensive growth and damage of muscles (Hagiwara et al., 1989). Its higher activity in turkeys of fastgrowing lines, compared to the slow-growing birds, has already been proved as an indicator of the response to physical stress and muscle strain (Wilson et al., 1990; Kowalski et al., 2002). The very high activity of the intracellular enzymes, including mainly aspartate transaminase, creatine kinase and lactate dehydrogenase, observed in our study in FG turkeys, may - as reported by Menon et al. (2013) be a symptom of rhabdomyolysis, i.e., migration of muscle cell components to the blood stream as a result of muscle tissue degradation. This process develops as a result of external mechanical damages, extreme physical effort or acute ischemia of the large parts of muscles. Noteworthy is that within all analyzed groups of turkeys, activities of most of the enzymes either increased or decreased correspondingly to body weight of turkeys (Table 3), and hence relative to their growth rate $(\mathrm{SG}>\mathrm{SF}>\mathrm{FS}>\mathrm{FG}$ ) that was characterized in our previous work (Damaziak et al., 2015). The comparison of stress responsiveness of the analyzed pure lines of turkeys used in this study as parental components to produce crosses may be summarized as follows. The SG turkeys are more susceptible to stress and respond more strongly to fear induced by strong and short-term action of an external stress stimulus, which under favorable conditions may mobilize the body for quick response and fast escape (reaction of the hypothalamic-pituitary-adrenal axis). In the case of heavy FG turkeys being commercial meat strains that were described as "docile" by Siegel (1989), the response to rapid environmental changes is milder. However, they bear prolonged physical effort much worse, which results in tissue and enzymatic changes.

The comparison of blood parameters of the analyzed pure lines of turkeys shows explicitly that the physiological response to stress is strongly genetically determined. In this study, however, of fundamental significance is the comparison of results obtained for turkey crosses. The multivariate analysis of blood parameters demonstrated that the hybrid differed significantly from both parental lines (Fig. 1). Although the SF and FS turkeys were classified to the same homogenous group (Fig. 1) based on parameters summarized in Table 1, the higher content of total protein and $H$, the lower content of $L$ and, consequently, a higher $H / L$ ratio in blood of SF turkeys suggest that this group of crosses exhibited a stronger response to stress stimuli compared to FS birds (Table 1). The concentration of cortisol in blood of SF turkeys should also be considered as elevated. Although the differences were not found significant, they were almost 2-fold higher compared to FS turkeys (Table 4). Interestingly, cortisol concentration in blood of FS turkeys was the lowest among all analyzed groups, which may indicate that $\mathrm{FG} \times \mathrm{SG}$ crossing enables producing crosses with the lowest responsiveness to short-term stress induced by sudden fear. Opposite inference may result from the analysis of differences in the lipid profile. It seems that the main stress response in FS turkeys involved increased blood concentrations of total cholesterol and LDLC cholesterol fraction (Table 2). According to Ahmed and Alamer (2011), the increase in cholesterol and triglyceride concentration in blood of birds may be linked with the enhanced mobilization of fat to produce metabolic water lost during transport. In our study, triglyceride concentration in blood of crosses was, however, at a similar level, and the period of water depravation was no longer than a few hours. There are no studies reported in literature that would explicitly indicate that stress modifies concentrations of individual fractions of cholesterol in blood of birds. However, surveys with humans show undoubtedly that stress predisposes for increasing concentrations of total cholesterol and LDLC fraction at unchanged or reduced concentration of the HDLC fraction (Scheuch et al., 1984; Shahnam et al., 2010). These authors explained that stress motivated the body for enhanced energy production during metabolic transformations, which resulted - most of all - in liver stimulation for LDLC synthesis. It is difficult to explain why the highest concentrations of all lipid fractions were found in the FS turkeys (Table 2). It may only be speculated that this is a defensive strategy of the body which is typical of this group of crosses. Future studies should address in-depth analysis of lipid metabolism and changes in concentrations of individual lipid fractions under the influence of stress in crosses originating from crossbreeding of fast-growing sires and slow-growing dams. Interesting is also that no significant differences were found in the activity of the analyzed enzymes in blood of the crosses (Table 3; Fig. 3). Dendrogram 3 indicates that both SF and FS turkeys were more similar to the SG turkeys regarding blood activity of the analyzed enzymes.

Results achieved in our study demonstrate that each of the analyzed genetic groups of turkeys differed in non-specific systemic stress responsiveness, which may be due to the fact that various lines exhibit different responses in the same environmental conditions as a result of the genetic-environment interaction (Siegel, 1989). It explains, most of all, differences observed between the pure lines of turkeys. According to Falconer and Mackay (1996), the crossbreeding of two populations responding differently to external stimuli enables the production of crosses which - as a result of the additive genetic variation - differ from both parental forms. This is because when some genes predominate in one specific direction and the other ones in the other direction, then their effects usually neutralize one another. Similarity to one of the parental forms may, in turn, occur upon the effect of other factors, like maternal or sire effects within reciprocal crosses. In poultry, maternal effects can include incubation environment, egg composition, maternal antibodies, and cytoplasmic 
or mitochondrial inheritance. Among the analyzed parameters for which the cross effect was significant $(P>0.05)$, only the concentrations of total cholesterol and LDLC assayed in blood of crosses were more similar to these determined in blood samples of the pure maternal line (Table 2; Fig. 2). Investigations concerning parental effects on the hematological and biochemical blood markers in birds are sparse. However, Velleman and Nestor (2004) confirmed a negative significance for the maternal effect regarding creatine kinase concentration in blood of turkeys, whereas Odeh et al. (2003b) showed that corticosterone blood concentration in quails depended mainly on the general combining ability, average line effects, and maternal effects. Although in our study the concentration of cortisol was determined by the cross effects, it is easy to notice that its value was affected to a greater extent by the sire line (Table 4), likewise total protein, $H$ (Table 1), aspartate transaminase and cholinesterase (Table 3). The sire effects are often neglected in studies conducted with poultry, probably because they are limited to gene inheritance determined by the sequence of exclusively nuclear DNA.

The confirmed significance of the cross effects may explain the similarity of crosses to one of the parental lines in terms of a selected trait. For generation F1, being a progeny from crossing two pure lines - the variability may also be due to heterosis also referred to as "hybrid vigor". Considering the 22 parameters analyzed in our study, both groups of crosses were superior over both parental forms only with respect to albumin concentration (Table 1). The negative heterosis confirmed for concentrations of creatinine (Table 1) and alanine transaminase (Table 3 ) resulted from higher values of both these parameters in both pure lines, compared to both groups of crosses. Results of the negative heterosis confirmed for aspartate transaminase and lactate dehydrogenase (Table 3) should, however, not be overestimated as they are probably caused by high values assayed in blood samples of FG turkeys, which was discussed earlier (see above). The confirmed effect of heterosis on cortisol concentration in blood of the analyzed turkeys is due to its very low concentration in blood of FS birds (Table 4). The fact that sparse attention was paid in literature to the effects of heterosis on the concentration of glucocorticoids in blood of turkeys impairs discussion regarding this research problem. Only Odeh et al. (2003b) analyzed the influence of heterosis on corticosterone blood concentration in Japanese quails, but they failed to confirm its significance in any of the crosses of 29 generations of 3 lines.

To the best knowledge of the authors, this article is the first report concerning differences in the physiological response to stress of two lines of turkeys with such a large genetic distance and of their reciprocal crosses. Study results demonstrate that each of the four analyzed genetic groups of turkeys exhibited a different response to stress. It would be naive to expect that such factors as few-hour fasting, catching or transport would not induce stress in any live animal, but the way an animal responds to stress may be fundamen- tal for production practice. If the reciprocal crosses of SF and FS turkeys, crossbred for the need of this particular experiment, in the future were used in the production system with the access to free range (i.e., alternative to intensive), then consecutive studies should be focused on bird response to stress under such production conditions. All the more that the response to stress in an outdoor system may be deemed a desirable behavior. Finally, the current findings indicate that the level of stress measured via hematological and biochemical blood markers is in most cases determined by additive genetic variation and to a lesser extent by maternal and sire effects, whereas during crossbreeding the fast-growing commercial BUT Big-6 line and slow-growing local Bronze turkeys the effects of heterosis should not be expected in the case of most of the analyzed parameters.

\section{Data availability}

The original data of the paper will be available upon request to the corresponding author.

Competing interests. The authors declare that they have no conflict of interest.

Acknowledgements. This study was part of the project "Maternal effects on performance and meat quality of turkeys" (accounting records: 50510070300-K0022699), financed by the Warsaw University of Life Sciences - SGGW, Warsaw, Poland.

Edited by: M. Mielenz

Reviewed by: two anonymous referees

\section{References}

Ahmed, A. S. and Alamer, M. A.: Effect of short-term water restriction on body weight, egg production, and immune response of local and commercial layers in the late phase of production, Asian Austral. J. Anim., 24, 825-833, 2011.

Anonymous: Act on Experiments on Animals of 21 January 2005 (Act 2005 No. 33 item 289), 2005.

Chikumba, N., Swatson, H., and Chimonyo, M.: Hematological and serum biochemical of chickens to hydric stress, Anim., 79, 15171522, 2013.

Damaziak, K., Michalczuk, M., Zdanowska-Sąsiadek, Ż., Niemiec, J., and Gozdowski, D.: Variation in growth performance and carcass yield of pure and reciprocal crossbred turkeys, Ann. Anim. Sci., 1, 51-66, 2015.

Damaziak, K., Pietrzak, D., Michalczuk, M., Adamczak, L., Chmiel, M., Florkowski, T., and Gozdowski, D.: Early and $24 \mathrm{~h}$ post-mortem changes in breast muscle quality traits of two turkeys genotypes and their reciprocal crosses, raised under semi-confined conditions, Brit. Poultry Sci., 57, 51-62, 2016.

Erasmus, A. M., Lee, H. C., Kang, I., and Swanson, J. C.: Fear responses and postmortem muscle characteristics of turkeys of two genetic lines, Brit. Poultry Sci., 94, 2018-2026, 2015. 
Falconer, D. S. and Mackay, T. F.: Introduction to Quantitative Genetics, 4th ed., Addison-Wesley, Essex, UK, ISBN-13: 9780582243026, 1996.

Forkman, B., Boissy, A., Meunier-Salaün, M. C., Canali, E., and Jones, R. B.: A critical review of fear tests used on cattle, pigs, sheep, poultry and horses, Physiol. Behav., 92, 340-374, 2007.

Hagiwara, Y., Shimo-Oka, T., Okamura, K., and Ozawa, E.: Basis for the assay of myogenic cell growth using creatine kinase activity as an index, with special reference to measurement of power ratio of transferrins in growth promotion, Jap. J. Pharmacol., 49, 53-58, 1989.

Hochleithner, M.: Biochemistries, in: Avian Medicine: Principles and Application, edited by: Ritchie, B. W., Harrison, G. J., and Harrison, L. R., 223-244, Wingers Publishing Inc., Lake Worth, FL, ISBN-10: 0-9636996-0-1, 1994.

Huff, G., Huff, W., Rath, N., Donoghue, A., Anthony, N., and Nestor, K.: Differential effects of sex and genetics on behavior and stress response of turkeys, Brit. Poultry Sci., 86, 1294-303, 2007.

Ilori, B. M., Peters, S. O., Yakubu, A., Imumorin, I. G., Adeleke, M. A., Ozoje, M. O., Ikeobi, C. O. N., and Adebambo, O. A.: Physiological adaptation of local, exotic and crossbred turkeys to the hot and humid tropical environment of Nigeria, Acta Agr. Scand. A-An., 61, 204-209, 2011.

Jóźwik, A., Śliwa-Jóźwik, A., Bagnicka, E., and Kołątaj, A.: The influence of selection on reaction to stress in mice, IX. Effect of dietary protein level on activity of lysosomal enzymes in liver and kidney, J. Anim. Breed. Genet., 120, 124-131, 2003.

Kowalski, A., Mormede, P., Jakubowski, K., and JedlińskaKrakowska, M.: Comparison of susceptibility to stress in two genetic lines of Turkeys broilers BUT-9 and Big-6, Pol. J. Vet. Sci., 5, 145-150, 2002.

Krams, I., Cîrule, D., Krama, T., and Vrublevska, J.: Extremely low ambient temperature affects haematological parameters and body condition in wintering Great Titr Parus major, J. Ornithol., 152, 889-895, 2011.

Luc, D. D., Bo, H. X., Thomson, P. C., Binh, D. V., Leroy, P., and Farnir, F.: Reproductive and productive performances of the stress-negative Piétrain pigs in the tropic: the case of Vietnam, Anim. Prod. Sci., 53, 173-179, 2013.

Menon, D. G., Bennett, D. C., Schaefer, A. M., and Cheng, K. M.: Hematological and serum biochemical profile of farm emus (Dromaius novaehollandiae) at the onset of their breeding season, Brit. Poultry Sci., 92, 935-944, 2013.
Odeh, F. M., Cadd, G. C., and Satterlee, D. G.: Genetic characterization of stress responsiveness in Japanese Quail. 1. Analyses of line effects and combining abilities by diallel crosses, Brit. Poultry Sci., 82, 25-30, 2003a.

Odeh, F. M., Cadd, G. C., and Satterlee, D. G.: Genetic characterization of stress responsiveness in Japanese Quail. 2. Analyses of maternal effects, additive sex linkage effects, heterosis, and heritability by diallel crosses, Brit. Poultry Sci., 82, 31-35, 2003b.

Rosochacki, S. J., Piekarzewska, A. B., Połoszynowicz, J., and Sakowski, T.: Genetic differences in brain monoamines level in Petrain and Duroc pigs expose to acute restraint stress, J. Anim. Breed. Genet., 120, 192-209, 2003.

Scheuch, K., Pietruschka, W. D., Eckhardt, G., Reinelt, D., and Reuter, W.: HDL and LDL cholesterol changes in psychological stress in relation to stress experience, Z. Gesamte inn. Med., 39, 273-277, 1984.

Shahnam, M., Roohafza, H., Sadeghi, M., Bahonar, A., and Sarrafzadegan, N.: The correlation between lipid profile and stress levels in central Iran: Isfahan Healthy Heart Program, ARYA Atheroscler. J., 6, 102-106, 2010.

Sheriff, M. J., Dantzer, B., Delehanty, B., Palme, R., and Boonstra, R.: Measuring stress in wildlife: techniques for quantifying glucocorticoids, Oecologia, 166, 869-887, 2011.

Siegel, H. S.: Stress, strains, and resistance, Brit. Poultry Sci., 36, 3-22, 1995.

Siegel, P. B.: The genetic-behavior interface and well-being of poultry, Brit. Poultry Sci., 30, 3-13, 1989.

StatSoft Inc.: STATISTICA (Data Analysis Software System), Version 12, available at: www.statsoft.com (last access: 10 June 2015), 2013.

Szabó, A., Mézer, M., Horn, P., Sútő, Z., Bázár, G., and Romvári, R.: Developmental dynamics of some blood biochemical parameters in the growing turkey (Meleagris gallopavo), Acta Vet. Hung., 53, 397-409, 2005.

Śliwa-Jóźwik, A., Jóźwik, A., and Kołątaj, A.: Influence of exogenous glutathione (GSH), as stress factor, on the activity of lysosome enzymes in some organs of mice, Arch. Tierzucht, 45, 307314, 2002.

Velleman, S. G. and Nestor, K. E.: Inheritance of breast muscle morphology in turkeys at sixteen weeks of age, Brit. Poultry Sci., 83, 1060-1066, 2004.

Wilson, B. W., Nieberg, P. S., Buhr, R. J., Kelly, B. J., and Shultz, F. T.: Turkey muscle growth and focal myopathy, Brit. Poultry Sci., 69, 1553-1562, 1990. 